\title{
Complementaridade entre educação não formal e formal no Programa Educacional Girassol
}

\author{
Complementarity between non formal and formal education in the Programa Educacional Girassol
}

Complementariedad entre la educación no formal y formal en el Programa Educacional Girassol

\author{
Marcos José de Aquino Pereira ${ }^{1}$ \\ Universidade FEderal de São Carlos, UFSCAR, São Carlos-SP, Brasil
}

\begin{abstract}
RESUMO
Este artigo busca explicitar a relação de complementaridade entre Educação Não Formal e Educação Formal presentes no Programa Educacional Girassol, em Águas de São Pedro-SP, tendo como objetivo refletir sobre as possibilidades oferecidas pela Educação Não Formal à aprendizagem e ao desenvolvimento dos seus educandos na Educação Formal, sob a perspectiva de que esse papel complementar ultrapasse a função de apoio à aprendizagem escolar, podendo proporcionar também sua ampliação. Metodologicamente, mergulhamos na leitura de autores/as, com o enriquecimento da entrevista concedida por Jaume Trilla, da Universidade de Barcelona, além da aplicação de questionários, produção de textos, desenhos para os/as educandos/as do programa e entrevistas com educadores/as, indicando que o mesmo tem desenvolvido atividades com perceptível impacto para os/as educandos/as em sua vivência, redundando em seu melhor desempenho escolar e desenvolvimento integral, promovendo a equalização de oportunidades de aprendizagens, que respondam aos desafios de uma formação humanista.
\end{abstract}

Palavras-chave: Educação Integral. Educação Não Formal. Educação Formal.

\begin{abstract}
This article aims to clarify the relationship of complementarity between Non-Formal Education and Formal Education presents in Programa Educacional Girassol, in Águas de São Pedro-SP, we having how objective to reflect about the possibilities offered by non-formal education to learning and development of their learners in formal education, the prospect is that this complementary role goes beyond the function support school learning, and can also provide its expansion. Methodologically, we plunged in the reading of authors, with the enrichment of the interview by Jaume Trilla, University of Barcelona, in addition to the questionnaires, production of texts, drawings for students and interviews with teachers, showing that the program has been working with noticeable impact on learner in their experience, resulting in their school performance and their greater integral development, promoting the equalization of opportunities for an learning, thus respond to the challenges a humanistic education.
\end{abstract}

Keywords: Integral Education. Non-Formal Education. Formal Education.

\section{RESUMEN}

Este artículo busca explicitar la relación de complementariedad entre Educación No Formal y Educación Formal presentes en el Programa Educacional Girassol, en Águas de São Pedro-SP con el objetivo de reflexionar sobre las posibilidades ofrecidas por la Educación No Formal al aprendizaje y al desarrollo de sus/as educandos/as en la Educación Formal, desde la perspectiva que ese papel complementario sobrepase la función de apoyo al aprendizaje escolar. Metodológicamente, se sumergió en la lectura de autores/as, con el enriquecimiento de la entrevista concedida por Jaume Trilla, de la Universidad de Barcelona, además de la aplicación de cuestionarios, producción de textos, dibujos para los/as estudiantes del programa y entrevistas con educadores, demostrando que ha desarrollado actividades con perceptible impacto para los/as educandos/as en su vivencia, redundando en su mejor desempeño escolar y en su mayor desarrollo integral, promoviendo la ecualización de oportunidades de un aprendizaje integral, que responda más plenamente a los desafíos de una formación humanista.

Palabras clave: Educación Integral. Educación No Formal. Educación Formal.

\footnotetext{
1 Doutorando em Educação pelo Programa de Pós-Graduação em Educação da UFSCar. E-mail: marcosdiaquino@gmail.com
} 


\section{INTRODUÇÃO}

Entendendo que a pesquisa "Vislumbres da complementaridade entre Educação Não Formal e Formal no Programa Educacional Girassol" ${ }^{2}$ contribuiu para a implementação do Ensino Integral na rede municipal de Águas de São Pedro-SP, o que se efetivou no ano de 2018, estendendo assim a todos os alunos das escolas municipais as diversas ações educativas, realizadas no Programa Educacional Girassol (PEG), acreditamos ser válido registrar e divulgar essa realidade para que possa servir de inspiração para o despertar de outras ações que pensem em educandos/as como seres integrais.

As atividades de convivência, diálogo, práticas esportivas e culturais realizadas no PEG voltam-se para a "vida de qualidade" (BRANDÃO, 2005, p. 31) que se pauta por uma perspectiva de superação do conceito de qualidade de vida, preconizado pela economia globalizada de mercado, em prol de um viver e conviver que promova a cultura da paz, o que ali se manifesta através de aulas de judô e de flauta, natação, brincadeiras coletivas, danças, cultivo da horta, Pracatum $^{3}$, caminhadas pela cidade e pelo parque municipal, entre outras.

Tendo como pano de fundo a perspectiva de que a realidade educacional brasileira apresenta desafios que exigem uma abordagem que contemple de maneira mais ampla a complexidade das relações envolvidas no "processo de ensino e de aprendizagem"4 (GONÇALVES JUNIOR; RAMOS; COUTO, 2003), este artigo explicita impactos e possibilidades oferecidas pela Educação Não Formal (ENF) à aprendizagem, ao desempenho e ao desenvolvimento dos seus educandos e educandas na Educação Formal (EF), inclusive vislumbrando-se a própria ampliação da perspectiva do que seja uma educação integral, pautada por uma visão educativa que entenda e promova a possibilidade de transcendência do ser humano (ser mais) (GONÇALVES JUNIOR, 2009), dentro da perspectiva da Motricidade Humana, entendida "[...] como a energia para o movimento intencional da transcendência ou da superação" (SÉRGIO, 2003, p. 18), que parte de uma abordagem do movimento enquanto fenômeno da corporeidade, em que se destaque a intencionalidade em sua relação com as vivências da emoção, da cultura e dos projetos pessoais e sociais (SÉRGIO; TORO, 2005), sendo essencial

[...] a experiência originária, donde emerge também a história das condutas motoras do sujeito, dado que não há experiência vivida sem a intersubjetividade que a práxis supõe. $O$ ser humano está todo na motricidade, numa contínua abertura à realidade mais radical da vida (SÉRGIO et al., 1999, p. 17-18).

Inicialmente o que nos preocupava e ensejou essa pesquisa foi a preocupação com o fracasso escolar que se manifesta segundo Patto (1999) sob as formas da repetência e da evasão escolar, visão essa que foi se ampliando e se modificando para o nosso entendimento conforme a pesquisa ia avançando, mas que, em um primeiro momento, lançou-nos à busca não por causas, o que já é estudado por vários/as autores/as, mas por opções para o seu combate e para a sua superação.

\footnotetext{
${ }^{2}$ Pesquisa de mestrado em educação, defendida em 2015, na UNISAL, sob a orientação da Prof. ${ }^{\text {a }}$ Dr. $^{\text {a }}$ Renata Sieiro Fernandes.

3 Aulas de percussão e ritmo, utilizando-se de instrumentos construídos com material reciclado, normalmente latas, que se materializa na formação de um grupo que se apresenta em diversos eventos na cidade.

${ }^{4}$ Perspectiva em oposição ao binômio ensino-aprendizagem, defendendo que o ensino e a aprendizagem devem ser entendidos como distintos, podendo ocorrer simultaneamente ou não.
} 
Essa busca nos colocou em contato com a ENF, que nos conduziu aos projetos dessa modalidade educativa no município de Águas de São Pedro, cidade que obteve o primeiro lugar em educação no Índice de Desenvolvimento Humano Municipal (IDH), segundo divulgado em 2013 pelo Programa das Nações Unidas para o Desenvolvimento (PNUD), com a pontuação de 0,825 (IPEA, 2013), chamando nossa atenção exatamente à existência de ações de ENF num município com baixo índice de evasão escolar e de crianças com faixa-etária considerada adequada para cada ano (um indicativo mais efetivo de baixa repetência), o que nos levou ao questionamento "pode existir alguma relação entre a existência de ações de ENF e a menor evasão e o melhor desempenho na educação escolar nesse município?”.

Diante disso, nos propusemos a realizar uma pesquisa de cunho predominantemente qualitativo, mas considerando alguns aspectos quantitativos, que teve o objetivo de estudar as possibilidades da ENF como auxiliar a EF no combate ao fracasso escolar, objetivo esse que, pelo próprio desenvolvimento da pesquisa, e pelo desvelamento dos seus resultados, nos enveredou para as ideias da complementaridade e da educação integral do ser humano.

\section{Percurso metodológico}

Ao se estudar as ações de ENF presentes no município de Águas de São Pedro, elegeu-se como base da pesquisa o PEG, devido a sua maior abrangência, organização e relação mais perceptível com a aprendizagem escolar.

O PEG foi oficializado em 8 de outubro de 2012 pela lei municipal 1640 da Estância Hidromineral de Águas de São Pedro, existindo entretanto desde 2007, quando foi criado pelo Decreto 3453/07, como Núcleo Saber e Ser, para o desenvolvimento de atividades de reforço e recuperação da aprendizagem, em continuidade ao período escolar, responsável por promover atividades de cunho social, desenvolvimento da cidadania, projetos educacionais de artes, esportes e meio ambiente (ÁGUAS DE SÃO PEDRO, 2012).

Tendo como base a epistemologia da complexidade de Edgard Morin (2007), em que "[...] o pensamento complexo aspira o conhecimento multidimensional" (p. 151) entendemos ser necessária uma abordagem que englobasse vários aspectos da realidade ali existente, especialmente sobre a percepção dos educandos e das educandas sobre o PEG e sobre o impacto desse no seu desenvolvimento escolar. Também buscamos conhecer a percepção dos educadores, educadoras, coordenadora do projeto, dos professores e professoras da escola regular, e também da secretária da educação municipal.

Consideramos ainda as nossas observações e impressões sobre o local, os ambientes, o canto dos pássaros, o aroma das flores e plantas ali presentes, a paisagem dos passeios realizados durante as visitas e o seu impacto nos comportamentos, as conversas informais ali ocorridas com funcionários e funcionárias, parentes dos educandos e educandas, educadores e educadoras e toda gente que por ali passou naquele período e vivenciou essa singular experiência de convivência.

O retorno obtido nas respostas ultrapassou essa meta e redirecionou a pesquisa para os impactos que o programa gerava nos âmbitos de desenvolvimento integral das crianças.

Para nossa coleta de dados, que teve como parâmetro a perspectiva de Antônio Chizzotti (1998) foi elaborado e aplicado um questionário com perguntas fechadas e abertas na segunda quinzena do mês de setembro de 2014, e abrangeu 22 educandos e 
28 educandas, com idades entre 8 e 12 anos, alunos e alunas do $3^{\circ}$ ao $5^{\circ}$ ano do ensino fundamental nos períodos matutino e vespertino, todos/as alfabetizados/as, sob o critério de participação voluntária, mediante a autorização dos responsáveis, através de Termo de Consentimento Livre e Esclarecido (TCLE), de respostas ao questionário, produção de textos, desenhos e respectivas interpretações, e imagens fotográficas.

Diante da variedade de impressões sobre as atividades do PEG expressas pelos/as educandos/as nas respostas às questões abertas, sentimos a necessidade de aprofundálas, sendo criado um novo instrumento solicitando-se que eles e elas redigissem uma pequena redação esboçando "como o PEG ajuda a ser melhor na vida e na escola", partindo essa formulação da temática da análise prévia dos resultados dos questionários, em que as respostas dos/as educandos/as indicaram que havia algo além do apoio à aprendizagem escolar que percebiam em relação ao PEG.

Criamos também um instrumento que fosse mais adequado para os educandos e educandas em processo de alfabetização, com a proposição da realização de desenhos para as crianças frequentes ao estágio Solzinho, do $1^{\circ}$ ano do Ensino Fundamental da educação escolar, com foco no que o Programa ajuda a ser melhor na vida e na escola para esta, e para os do estágio Semente, do $2^{\circ}$ ano, sobre o que mais gosta no PEG. Essa atividade foi aplicada na primeira semana de outubro de 2014, abrangendo 35 crianças.

A análise desses instrumentos seguiu a mesma perspectiva da epistemologia da complexidade de Edgar Morin (2007) utilizada na coleta dos dados, sendo relacionada como a fundamentação principal da pesquisa que teve por base o pensamento de Jaume Trilla (2008), presente em suas obras, sendo aprofundado pela entrevista concedida pelo autor especialmente para essa pesquisa, aclarando diversos pontos e ampliando a visão sobre aspectos da relação entre ENF e EF, possuindo questões sobre a relação de interdependência entre a EF e ENF, sobre a possibilidade de um sistema que integrasse ambas as modalidades educativas, a existência ou não de metodologias específicas da ENF, entre outras.

\section{Caracterização do PEG}

No PEG a divisão dos educandos se faz em 4 estágios relacionados aos anos da escola: os alunos e alunas que frequentam o $1^{\circ}$ ano, integram o estágio Solzinho; do $2^{\circ}$ ano, Semente; do terceiro ano, Terra; e a união dos alunos do quarto e quinto anos, sob a denominação de Água.

Ilustração 1 - Diversas atividades realizadas pelos educandos e pelas educandas no PEG.

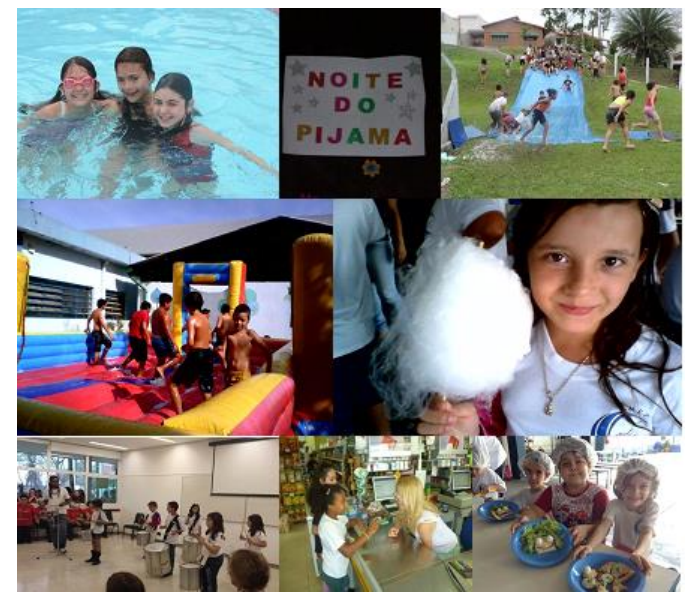

Fonte: Acervo do PEG. 
O programa oferece alimentação com preparação supervisionada por nutricionista, com variado cardápio, contando com 2 refeições no período da manhã (café da manhã e lanche), almoço e 1 refeições no período da tarde (lanche).

Os educandos e as educandas dividem o seu tempo entre diversas atividades, projetos e ações, os quais passaremos a apresentar, com base em nossas observações, em entrevistas e conversas:

- Pracatum: aulas de percussão e ritmo, utilizando-se de instrumentos construídos com material reciclado, com apresentações em diversos eventos na cidade;

- Apoio a Lição de Casa: atividade de apoio e orientação para que os/as educandos/as realizem as lições de casa dos diversos componentes curriculares da escola;

- Reforço escolar: aulas de reforço dos diversos componentes curriculares da Base Comum do Ensino Fundamental, visando sanar dúvidas e apoiar o estudo dos/as educandos/as na escola;

- Informática: aulas e utilização dos computadores, em laboratório específico, com realização de diversos projetos;

- Aulas de Balé e Jazz: em parceria com a Academia de dança Galpão do município vizinho, São Pedro;

- Aulas de Judô: prática de luta e treinos;

- Educação Física: prática de diversas modalidades esportivas, como futebol, vôlei, basquete e ginástica rítmica;

- Natação: aulas e prática de natação, com recreação nas piscinas municipais e também com a formação e treino de equipes para competição;

- Projetos SENAC: parceria com o SENAC Grande Hotel de Águas de São Pedro, com a realização de oficinas de teatro, palestras sobre nutrição e temas ligados à alimentação e saúde, atividades de recreação com brincadeiras e jogos;

- Culinária: aulas de culinária e nutrição com preparação de alimentos que são consumidos pelas crianças, utilizando verduras plantadas por eles e elas na horta;

- Música: aula de teoria, apreciação e prática musical diversificada;

- Tempo livre: período de descanso, brincadeiras, conversas, em que os educandos e as educandas têm a liberdade de escolher o que fazer, inclusive descansar ou dormir;

- Passeios: variadas visitas e atividades fora do espaço físico do Programa, como por exemplo, o passeio de trenzinho turístico da cidade, ou a visita ao Parque Municipal Octávio Moura Andrade, com cerca de 1 quilômetro quadrado de área verde com trilhas;

- Noite do pijama: atividade em que os educandos e as educandas dormem no espaço interno do projeto, participando de diversas gincanas e brincadeiras, vestidos com pijamas e podendo levar seus brinquedos prediletos;

- Sacola de valores: durante o ano são trabalhados 5 valores com as crianças, a saber: Respeito Mútuo, Tolerância, Solidariedade, Responsabilidade e Justiça, através do envio de uma sacola contendo 3 livros, dentre os quais o Livro das Virtudes para Crianças, de W. J. Bennet (1997), 5 historinhas escolhidas e adaptadas pela equipe de educadores, e folha explicativa sobre os valores citados e um caderno de registro, objetivando que a família utilize o material para debater o tema escolhido, gerando desenhos, comentários e reflexões feitas pelos pais, mães e/ou responsáveis e pelos educandos e educandas, no caderno de registro, sendo em seguida enviado para outra família, que lê o que foi escrito e procede da mesma forma; 
- Futuro Jovem Brasileiro: acompanhamento mensal individual de cada criança através de um relatório preenchido pela família indicando o desenvolvimento da autonomia dela em casa.

Ao final do ano de 2014, o PEG contava com 44 educandos e educandas no período da manhã e 64 à tarde, estando todas as crianças matriculadas em escola municipal em contraturno.

\section{A Visão de COMPLEMENTARIDAdE ENTRE EdUCAÇÃo NÃo FORMAL E EdUCAÇÃo FORMAL}

Quando falamos sobre o surgimento moderno da Educação Não Formal ${ }^{5}$, podemos relacioná-lo à própria cristalização da educação escolar no final do século XIX, sendo que o termo em si surgiu apenas na década de 1960, cunhado na obra The world educational crisis, de P.H. Coombs (1968), mas recebendo sua distinção dos demais tipos de educação apenas em 1974, na obra Attacking rural Poverty: How Nonformal Education Can Help, de Coombs e Ahmed (1974), devido à ampliação de ações dessa modalidade educativa exatamente num momento em que a modalidade formal passava por um processo de forte reflexão acerca de sua impossibilidade de responder a toda demanda que a sociedade lhe apresentava (TRILLA, 2008).

Aqui começam a se polarizar vertentes que enxergarão a ENF como alternativa à educação escolar e as que a verão como importante complemento ou ampliação a essa.

Para tratarmos dessa relação e dada à amplitude de definições existentes, adotaremos a conceituação de ENF como:

[...] toda aquela que é mediada pela relação de ensino-aprendizagem, tem forma, mas não tem uma legislação nacional que a regula e incide sobre ela. Ou seja, uma série de programas, propostas, projetos que realizam ações e interferências, que são perpassados pela relação educacional, mas que se organizam e se estruturam com inúmeras diferenças - um leque bastante amplo de possibilidades contempla a ENF (GARCIA, 2005, p. 115).

A diferenciação entre ENF e EF é explicada por Trilla em sua fala, na entrevista concedida especialmente para essa pesquisa, no trecho que se segue:

Processos educativos que se dão tanto na EF como na ENF. A diferença, esta diferença, é o que colocamos dentro deste "cajón"6 de EF, é toda aquela educação que forma parte do sistema de ensino de um país estabelecido em suas leis, e está educação leva a aquisição de certificados e títulos oficiais, né? Portanto o que temos como EF são o ensino primário, o ensino secundário, a formação universitária, a formação profissional, etc., tudo aquilo que conduz a títulos acadêmicos. Então o que temos aqui são processos e ensinamentos educativos, que sendo intencionais, sendo sistemáticos e metódicos, configuram-se a partir de processos claramente diferenciados de outros processos sociais, culturais, etc. Não conduzem a aquisição dos títulos acadêmicos que da EF (AQUINO-PEREIRA, 2015, p. 74).

\footnotetext{
${ }^{5}$ Considerando que o autor base de nossa pesquisa é Jaume Trilla (2008), que utiliza em sua obra o termo Educação Não Formal, mantivemos tal nomenclatura em todo artigo, embora cientes da discussão na área de Educação sobre o uso desta expressão e a possibilidade de uso da expressão Educação Não-Escolar.

${ }^{6}$ Ao usar o termo "cajón", Trilla refere-se a "cajón de sastre", fazendo uma comparação entre a ENF e esse móvel, que seria uma gaveta onde se colocam variados objetos, sendo uma metáfora da grande diversidade e variedade presente nessa modalidade educativa.
} 
Jaume Trilla vê uma relação de interdependência entre ambas:

[...] eu creio que esta interdependência é, digamos, crucial e inevitável. Porque digamos que na teoria e nos conceitos podemos separar que aqui está a EF e aqui temos a ENF, né? Podemos ver que a EF é tudo isso, as escolas primárias, os institutos de secundária (ensino fundamental e médio), as universidades etc., e na ENF há outros conjuntos de instituições e processos educativos que são diferentes. É claro, essa separação é verdade em nível teórico e conceitual, mas quando as pessoas que usam a EF e a ENF, tudo isso se complica, tudo isso se relaciona (AQUINO-PEREIRA, 2015, p. 207).

Trilla trata dessas relações entre as duas modalidades educativas em sua obra "A educação não formal", apresentando-a em três âmbitos: interações funcionais, intromissões mútuas e permeabilidade e coordenação, tendo claro que:

A educação do ponto de vista dos seus efeitos é um processo holístico e sinergético [...] é uma espécie de interdependência que pode ser expressa diacronicamente (cada experiência educacional é vivida em função das experiências educacionais anteriores e prepara e condiciona as subsequentes), e também sincronicamente (o que acontece com a criança em determinado ambiente educacional tem relação com o que ela vive nos outros ambientes educacionais dos quais participa) (TRILLA, 2008, p. 45).

Sendo assim, as interações funcionais ocorrem de forma bastante complexa e intrincada. Para lançar um pouco de luz sobre essa entretecida realidade, o autor apresenta diversos tipos de relações possíveis:

- Relações de complementaridade: [...] aparece como uma espécie de complementaridade, uma espécie de partilha de funções, de objetivos, de conteúdos entre os diversos agentes educativos. Trata-se não obstante de diferenças de ênfase mais que excludentes: algumas instâncias atendem mais diretamente o lado intelectual, enquanto outras mais o afetivo ou social; algumas são concebidas para oferecer conteúdos gerais, enquanto outras para desenvolver habilidades muito específicas, algumas pretendem capacitar para o trabalho, enquanto outras atuam no âmbito do lazer etc.

- Relações de suplência ou de substituição. Às vezes, a ENF assume tarefas que são - ou deveriam ser- próprias do sistema formal, mas que ele não realiza de maneira satisfatória. [...]

- Relações de substituição. [...] a ENF, em certas ocasiões e contextos, foi vista até como substituto da EF. [...]

- Relações de reforço e colaboração. [...] programas dos meios de comunicação; atividades que instituições como museus, bibliotecas, fundações culturais põe à disposição das escolas; fazendas, instalações agrícolas, viagens para educação ambiental, empresas que colaboram em programas de educação permanente etc.

- Relações de interferência ou contradição. [...] A realidade do universo educacional, que inclui também o universo social em que se insere, é sempre muito mais heterogênea, com valores em conflito, com interesses opostos. (TRILLA, 2008, p. 46-49)

$\mathrm{Na}$ entrevista, ao ser solicitado que dissesse sobre qual dessas relações é atualmente ou conceitualmente mais forte, o autor diz:

Eu digo que, uma parte explico, que a relação entre os tipos de educação são de complementaridade, no sentido que agora que lhe explicava, às vezes são de suplência, às vezes são de ajuda ou colaboração com a EF, com a escola, 
etc., às vezes são de contradição. Vamos ver. Quais seriam as mais importantes? Eu acredito que as que deveriam ser mais importantes são primeiro as de complementaridade (AQUINO-PEREIRA, 2015, p. 212).

Também Barrie Brennan, da Universidade da Nova Inglaterra, relaciona ENF a $\mathrm{EF}$, criando três subtipos para a ENF, entende ser a sua primeira relação com a EF como complemento, a segunda como alternativa, e a terceira como suplemento (SIMSON; PARK; FERNANDES, 2007, p. 17-19).

É necessário abordar também certas possibilidades de conflitos, resistências e dificuldades presentes nessa relação, como, por exemplo, o risco de se gerar uma "escolarização" das ações de ENF, na medida em que, nomenclaturas, metodologias, organização, objetivos da EF, acabem sendo incorporados, ou acabem predominando nos espaços não formais.

Diante dessa realidade, uma perspectiva bastante interessante é a da "coordenação e permeabilidade" entre as modalidades educativas, defendida por Trilla, que entende ser bastante positiva a busca por uma sempre maior "porosidade" entre elas. Com isso se permite que, cada uma com suas características e gama de possibilidades, auxiliemse, complementem-se e ampliem-se com o objetivo de favorecer a aprendizagem e tornar mais efetiva a humanização.

$\mathrm{Na}$ entrevista, ao ser solicitado que explicasse melhor sua visão sobre essas propostas e tendências, e se seria possível vislumbrar um sistema de ensino que englobasse ambas as modalidades educativas, Trilla responde:

Eu não sei se poderia propor algo assim tão radical, tão drástico porque digamos que um sistema educativo que possa fazer as duas coisas de uma vez seria um sistema formal, inteiramente formal, eu diria. Outra coisa, quando eu falo de estabelecer relações mais estreitas entre a EF e ENF, me refiro sobretudo a por exemplo que a EF reconheça formalmente aquisições realizadas a partir da ENF. E isso já em parte está sendo feito, mas poderia ser muito mais (AQUINO-PEREIRA, 2015, p. 75).

Essa visão de integração, coordenação e permeabilidade, sendo entendidas como possibilidades de uma ação educativa mais rica, mais ampla e mais completa, que permita uma variedade de ações, de relações e de criações, encontra eco em diversos autores, como, por exemplo, em Gadotti (2005), que enfoca a ponte que se pode criar entre a comunidade e a escola, através da integração entre EF e ENF:

[...] defendo uma complementaridade entre o sistema formal e a grande variedade de ofertas de ENF, inclusive para enriquecer a $\mathrm{EF}$, reforçando assim modos alternativos de aprendizagem. Os obstáculos são muitos, inclusive o da superação de certas mentalidades que tentam avaliar a ENF através dos critérios da $\mathrm{EF}$, o que reduz muito a riqueza do saber construído por organizações e movimentos sociais no campo da ENF. [...] Para isso, precisamos construir uma nova cultura escolar, que leve em contra a identidade cultural do aluno na construção do seu itinerário educativo. Para isso, a integração EF e ENF na escola é importante. Para isso, ainda, o paradigma da educação popular, como Paulo Freire o desenvolveu, pode nos ser muito útil. Por último, gostaria de concluir dizendo que a harmonização entre a EF e a ENF nos sistemas educativos deverá contribuir para uma maior integração entre direitos humanos e a educação (p. 10-11, tradução nossa).

Podemos considerar que havendo tal complementaridade, haveria uma facilitação e potencialização das contribuições que a ENF pode realizar isoladamente, como: 
- consciência e organização de como agir em grupos coletivos;

- a construção e reconstrução de concepção (ões) de mundo e sobre o mundo; - contribuição para um sentimento de identidade com uma dada comunidade; - forma o indivíduo para a vida e suas adversidades (e não apenas capacitação para entrar no mercado de trabalho);

- quando presente em programas com crianças ou jovens adolescentes a ENF resgata o sentimento de valorização de si próprio [...] dá condições aos indivíduos para desenvolverem sentimentos de autovalorização, de rejeição dos preconceitos que lhes são dirigidos, o desejo de lutarem para ser reconhecidos como iguais (enquanto seres humanos), dentro de suas diferenças (raciais, étnicas, religiosas, culturais, etc.);

- os indivíduos adquirem conhecimento de sua própria prática, os indivíduos aprendem a ler e interpretar o mundo que os cerca (GOHN, 2006, p. 30).

\section{Como afirmam Fernandes e Garcia (2006):}

As perspectivas da ENF ajudam a evidenciar o quão importantes e válidas se tornam às experiências educativas e formativas desse tipo, ocorrendo paralelamente à frequência escolar; permitindo afirmar que a ENF seja vista, então, como mais uma possibilidade de vivência educativa, atuando em outros setores em que a EF não atua, sem competir com ela, mas visando complementá-la (p. 24).

Trilla, na entrevista, esboçará uma visão sobre educação integral, que também não a vê apenas como extensão do temporal da permanência na escola, e transcenderá, inclusive, e como já foi expresso anteriormente por ele próprio, a ideia de que a EF poderia dar conta, em si, de toda a educação do ser humano:

Vamos ver, quando eu falo da relação de complementaridade me refiro que entre a EF, a ENF e também a informal - mas aqui não há pergunta para ela (educação informal)- se complementam um pouco do mesmo sentido que dizia antes. [...] $\mathrm{O}$ ensino integral, o conceito de educação integral significa que a educação deve desenvolver de forma completa, harmônica, desenvolvendo a personalidade tanto no cognitivo, nos conhecimentos, no intelecto, etc., como o afetivo, o ético, o moral, o físico, a educação física, a educação estética, etc. Este seria o ideal da educação. $\mathrm{O}$ ensino integral teria que fazer tudo, mas pensava-se que uma só instituição educativa ou um só tipo de instituição educativa iria conseguir o ideal da educação integral. Não é possível pensar que a escola vá conseguir este desenvolvimento completo e harmônico e tal, do intelectual, do afetivo, do físico, do moral, etc. etc., que a educação da escola vá servir para que a pessoa se integrem na maioridade no mundo do trabalho e que vão desfrutar de seu tempo livre. Não há nenhuma instituição efetiva que alcance isto. Só deve conseguir através da ação complementária de diversas instâncias educativas, umas são formais, outras são não formais e outras informais (AQUINO-PEREIRA, 2015, p. 80).

$\mathrm{O}$ que nos permite entender essa complementaridade visando o desenvolvimento de variados âmbitos do indivíduo, numa ampliação de suas experiências, na oportunização de vivências que gerem aprendizagens diversificadas, singulares e significativas, em seu crescimento como ser humano, em uma educação integral e integrada, que valorize essas aprendizagens, sejam elas provindas da EF, da ENF e, por que não?, da educação informal. Em uma visão, como quer Trilla, de que "educação é educação" (AQUINO-PEREIRA, 2015, p. 207). 


\section{APRESENTAÇÃO DOS RESULTADOS}

Sendo bastante ampla a gama de informações obtidas na pesquisa que ensejou este artigo, apresentamos aqui as de maior relevância acerca da relação de complementaridade entre EF e ENF e como essa relação traz possibilidades para o desenvolvimento de uma educação integral do ser humano.

Começaremos a análise dos resultados da pesquisa pelas questões fechadas que revelaram a preocupante constatação de que 39 educandos/as dos 50 pesquisados/as afirmem possuir dificuldades em pelo menos uma disciplina escolar, o que perfaz um total de 78\%. Aqui fica o questionamento: considerando-se que essas percepções correspondam também à realidade da aprendizagem dessas disciplinas na escola, o que levou esses educandos a não desenvolverem dificuldades enquanto os outros as apresentarem? Como isso poderia ser revertido? Qual o papel da ENF diante desse quadro? Este último questionamento será abordado mais adiante, quando tratarmos dos cruzamentos dessas informações.

Aprofundando a reflexão sobre a percepção dos educandos sobre o Programa, temos agora as respostas às questões abertas, que demonstraram que entre as atividades que os educandos mais gostam se encontram as que envolvem ações práticas, com $73 \%$ das respostas, incluindo as atividades de educação física, treinos de ginástica, natação, aulas e práticas de música e dança, teatro, judô e o Pracatum, muitas das quais que envolvem o desenvolvimento da coordenação motora, como a culinária, por exemplo.

O tempo livre também foi citado em $11 \%$ das respostas, sendo algo peculiar da $\mathrm{ENF}$ ao se comparar com as rotinas escolares que muitas vezes buscam ocupar todo o tempo dos estudantes, sem que exista o tempo livre realmente, para a livre escolha do que fazer e até mesmo a livre opção de não fazer nada. É importante reforçar que tempo livre aqui não se refere a intervalo, nem a horário de almoço ou lanche, mas efetivamente a períodos sem atividade programada, em que os educandos optam por ler, conversar, descansar, brincar, e até mesmo "tirar uma soneca" utilizando os espaços internos e externos do PEG.

Ao solicitar que os educandos indicassem sua percepção sobre os impactos do PEG, confirmou-se nossa expectativa inicial, referente ao combate ao fracasso escolar, mais especificamente no elemento de frequência à escola, que pode impactar diretamente tanto em repetência quanto em evasão escolar, em que verificamos que $42 \%$ dos educandos e educandas acreditam que o PEG os ajuda a faltar menos na escola. Ainda sobre essa pergunta temos que $41 \%$ acreditam que ele ajuda na melhoria de seu desempenho nas disciplinas escolar.

Outro aspecto que chamou nossa atenção foi que 30\% das respostas afirmavam que o PEG ajuda a melhorar a autoestima, que se nos apresentou como algo inesperado nas questões abertas.

Outro aspecto que chamou nossa atenção foi que $30 \%$ das respostas afirmavam que o PEG ajuda a melhorar a autoestima, que se nos apresentou como algo inesperado nas questões abertas.

Sobre os resultados dessa questão, um ponto despertou nossa atenção, que nos levou exatamente à ideia da complementaridade. Estamos nos referindo ao fato de que o número de respostas que afirmam ser o PEG um auxiliar no desempenho escolar ser muito elevado, se considerarmos os educandos que, no mesmo questionário, responderam não possuir dificuldade em nenhuma disciplina. Essa aparente inconsistência nos levou a realizar um cruzamento entre os dados das diferentes questões com os dessa última, e os resultados foram surpreendentes se pensarmos em nosso ponto de partida relacionado apenas ao combate da repetência e evasão escolar. 
A primeira relação que percebemos, foi exatamente dentro do universo dos educandos que declararam não possuir dificuldade em nenhuma disciplina escolar, em que $91 \%$ responderam simultaneamente perceber que o PEG os ajuda a ter um melhor desempenho nas disciplinas escolares.

Chamou nossa atenção, sobretudo, a diferença de quantidades de respostas simultâneas a essas duas questões se compararmos o grupo de educandos sem dificuldade em nenhuma disciplina com o grupo de educandos com dificuldade em alguma(s)/todas disciplina(s), pois se no primeiro como já dito chegou a $91 \%$, no segundo não passa de 51\%, o que em nossa análise indica uma eficácia maior dessa ação de ENF sobre os educandos que se sentem sem dificuldade nas disciplinas escolares, o que é para nós, ante a visão da qual partimos, surpreendente e promissor, em uma nova perspectiva sobre as possibilidades de aplicação da ENF em nossa sociedade em conjugação com a EF, reforçando, desenvolvendo e ampliando aprendizagens e não apenas resgatando defasagens.

Essa tendência de haver um maior impacto sobre o grupo de educandos que se percebe como não tendo dificuldade em nenhuma disciplina escolar se confirma no aspecto emocional. Sobre a sua autoestima ser ajudada pelo PEG recebemos desse grupo $55 \%$ de respostas afirmativas, enquanto entre os que afirmaram possuir dificuldade em uma ou mais disciplinas esse percentual foi de $39 \%$.

Passando à análise das produções de textos apresentadas, percebemos a presença de respostas que abordam os âmbitos de apoio à aprendizagem escolar, de oferecimento de aprendizagens extras e da oportunidade de vivências e experiências diferenciadas, do desenvolvimento pessoal, emocional e coletivo, com grandes demonstrações de contentamento e carinho dos educandos para com o projeto e para com as pessoas com quem lá convivem. Isso está em sintonia com o que foi demonstrado nos outros instrumentos, permitindo uma maior explicitação e detalhamento.

Destacaram-se nas produções, as referências às aprendizagens desenvolvidas no âmbito pessoal e coletivo, mas também as que apoiam a aprendizagem escolar, em algumas frases escritas pelos educandos, como pela Renata ${ }^{7}$ em "[...] me ajudam na matérias de lição de casa etc.”. Também vemos Pedro expressar seu sentimento pelo projeto em "Eu gosto de tudo que tem no projeto", "É minha segunda família" respondeu Paulo e "Eu adoro participar do Projeto Girassol" escreveu Francisca. Para nós foi bastante significativa a frase dita por Heliodora, pois entendemos que poderia ser tido como um grande objetivo ou perspectiva educativa para a vida: "[...] me ensinam a ser feliz".

Encontramos também nessas produções pontos de desenvolvimento artístico, que inclui, por exemplo, "tocar flauta" como expressou Tainá e "bater lata" como respondeu Lourenço. Aparecem diversas menções da percepção do educando sobre o impacto do projeto em sua vida "[...] me ajuda a ser uma pessoa boa", destacado por Renato e "[...] não ficar em casa sozinho jogando no computador" esboçado por André, "[...] ajuda a não fica na rua", como respondeu Benedito, realidades essas, de isolamento e excesso de horas passadas na frente do computador, ou simplesmente de ficar na rua, às vezes em situações de risco, que são vivenciadas por muitas crianças, enquanto que, no PEG, a educanda Maria Cristina afirma "[...] preferir estar no projeto que a torna uma pessoa boa".

Partindo da perspectiva compartilhada por Luquet (1969), Lowenfeld (1977) e Pilar (1996) acerca da importância do desenho como forma de expressão e manifestação do universo interior da criança, nos propusemos a fazer uma interpretação do material

\footnotetext{
${ }^{7}$ Utilizamos pseudônimos para preservar a identidade das crianças. O mesmo recurso foi utilizado nos desenhos.
} 
produzido pelos educandos do PEG pertencentes aos estágios "Solzinho" e "Semente" tendo como objetivo cotejar relações entre esses e os resultados dos questionários aplicados aos educandos dos estágios "Terra" e "Água". Para a interpretação dos desenhos recorremos às próprias crianças, mostrando-lhes os desenhos por elas realizados e pedindo que falassem livremente o que queriam dizer, fazendo perguntas de aprofundamentos sobre alguns elementos do próprio desenho ou dos comentários das crianças, após isso foram registradas também as nossas considerações sobre as explicações.

A partir da proposta de realizar um desenho sobre o tema "O que você mais gosta no PEG?" os/as educandos/as do PEG frequentadores da $1^{\text {a }}$ série do ensino fundamental na escola regular produziram 15 desenhos, nos quais observamos algumas características bastante presentes: crianças sorrindo, a quase totalidade apresenta essas crianças em grupos, com a representação de diversas atividades desenvolvidas no PEG, como jogos de futebol, dança, judô, brincadeiras, tempo livre, descanso, horta, culinária etc. Alguns educadores/as também aparecem representados como figuras de estatura maior entre as crianças, esses também sempre desenhados sorridentes.

Ilustração 2 - Exemplos de desenhos produzidos pelos educandos do estágio "Solzinho" do PEG com crianças em grupo.
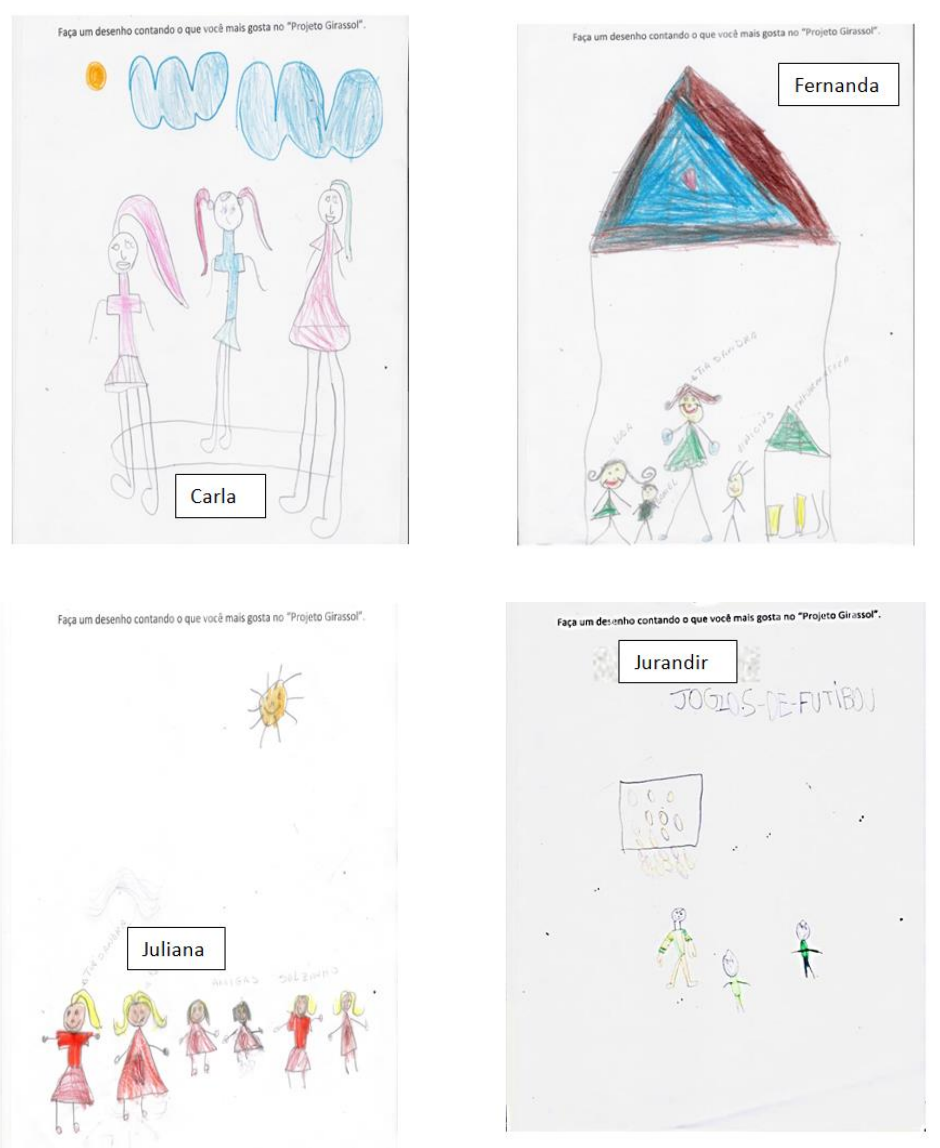

Fonte: Acervo do autor.

Com a mesma proposta, mas com um tema diverso, no caso "em que o PEG te ajuda a ser melhor em sua vida e na escola", os educandos do estágio "Semente", realizaram 22 desenhos. 
Ilustração 3 - Exemplos de desenhos produzidos pelos educandos do estágio "Semente" do PEG com crianças em situação de aula ou estudo.
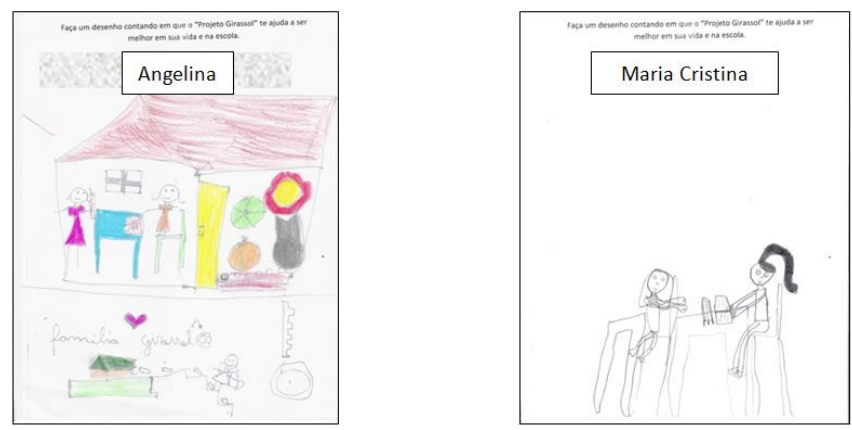

Fonte: Acervo do autor.

Destacaram-se 11 representações de crianças em alguma situação de aula ou estudo, ou com referência direta à escola. Encontramos 12 desenhos em que aparecem crianças em grupo ou pelo menos em dupla, realizando atividades do PEG, temos 3 representações de crianças cantando e uma fazendo referência ao Pracatum, com uma criança tocando um instrumento de percussão.

Ilustração 4 - Exemplos de desenhos produzidos pelos educandos do estágio "Semente" do PEG com crianças em atividades práticas.
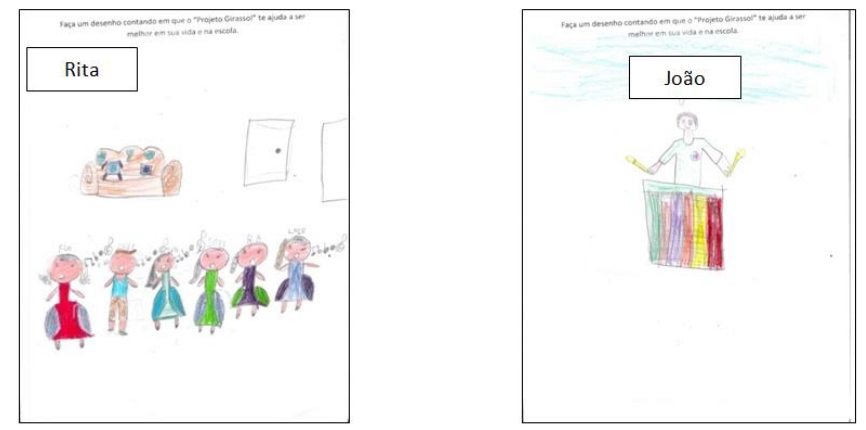

Fonte: Acervo do autor.

Mesmo as poucas representações de crianças sozinhas, transparece alegria com rostos sorridentes e execução de alguma ação, ou com brinquedos perto, ou representações de corações e arco-íris, incluindo-se uma menina cercada por brinquedos e animais, outra com um balão de festa. 


\section{Ilustração 5 - Exemplo de desenho produzido pelos educandos do estágio "Semente" do PEG com} criança sozinha.

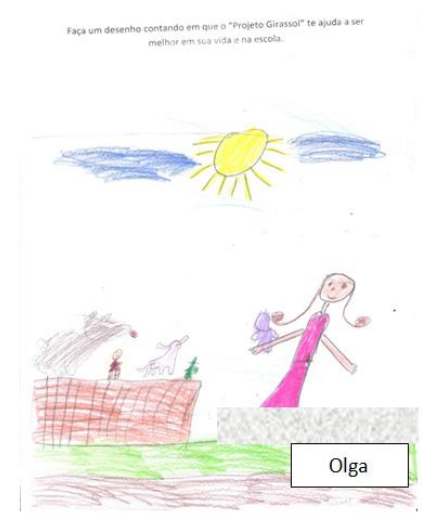

Fonte: Acervo do Autor.

Finalmente temos as respostas ao questionário expressas pelos professores/as da escola municipal e pelos educadores/as do programa que manifestaram reconhecer o papel do PEG, tanto como apoio à EF, com o resgate e reforço de conteúdos, quanto como ampliação das aprendizagens dessa, abordando temas que não lhe são frequentes, e até mesmo como capaz de desenvolver a autoestima e a motivação e o interesse pelo estudo, o que indiretamente auxilia a aprendizagem escolar, além de contribuir para a redução das faltas escolares.

\section{CONSIDERAÇÕES}

Ao contemplarmos um cristal multifacetado, temos sempre a impressão de que uma nova cor, uma diferente luz, um inesperado brilho vai se manifestar a cada novo instante, a cada mudança de posição, a cada aproximação ou afastamento durante a observação/vivência dessa experiência singular. A mesma sensação foi válida no estudo sobre a ENF em sua materialização no município de Águas de São Pedro.

A análise dos resultados dos instrumentos de coleta de dados vieram confirmar nossa primeira expectativa quanto ao ganho dos/das educandos/as com dificuldades de aprendizagem na EF, podendo auxiliar no combate ao fracasso escolar, que, após as reflexões surgidas durante essa pesquisa, a nosso ver não se restringe apenas à repetência e à evasão, visão com a qual iniciamos, mas inclui outras implicações como a passagem pela escola sem que se desenvolvam e nem se agreguem capacidades, valores e vivências significativas para o crescimento pessoal e social.

Ao mesmo tempo esses resultados impulsionaram a busca por uma maior amplitude em nossa perspectiva, aventando e demonstrando possibilidades de cotejamentos mais complexos, que também considerem o impacto positivo das ações da ENF na complementação da aprendizagem daqueles educandos que não apresentam dificuldades na escola regular, mas que enriquecem significativamente suas aprendizagens ao participarem de ações de ENF.

$\mathrm{O}$ especial destaque que os/as educandos/as deram às atividades práticas, que incluem a prática de esportes, danças, lutas, teatro, percussão, dentre outras, indicam um valor a elas inerentes na promoção da vida de qualidade (BRANDÃO, 2005), em que se considere a nossa percepção dos "[...] raios de sol, a sombra das árvores, o canto dos pássaros e as crianças desenvolvendo atividades educativas ao ar livre, em um processo 
de aprendizagem significativo e na valorização de si, dos colegas, e da vida" (AQUINO-PEIRERA, 2015, p. 167) pensando-se em uma formação integral do ser humano, que supere a dicotomia platônico-cartesiana de corpo e mente, em uma visão de transcendência, do ser mais, sob uma perspectiva da motricidade humana (SERGIO; TORO, 2005) que enseje a percepção do ser de modo integral, em harmonia com o ambiente, com os outros e consigo, como pudemos perceber ao acompanhar as atividades dos educandos do PEG, no espaço do programa, na piscina pública, nas caminhadas pelo centro da cidade ou nas trilhas pelo parque municipal.

Também o caráter de equalização das oportunidades de experimentação cultural, artística, esportiva e tecnológica, entre outras, ficou patente, revelado pelos resultados dos questionários, produções de texto, entrevistas, pela observação das diversificadas atividades do PEG. Acreditamos que algumas dessas experiências seriam muito difíceis senão inviáveis de serem vivenciadas por essas crianças, especialmente as provindas de famílias de baixa renda, se não existisse o programa.

É preponderante destacarmos a importância de que experiências de ENF específicas bem sucedidas tornarem-se políticas públicas, ampliando assim seu alcance e seu impacto e contanto com todos os recursos, não apenas econômicos, que lhe pode garantir a manutenção direta oferecida pela ação governamental, como ocorre em Águas de São Pedro, onde a existência do PEG foi garantida por força de lei municipal, tornando-se agora parte da educação regular, com a integralização de toda a rede de ensino da cidade, em que se ressalte que o município, possui $100 \%$ de sua educação básica pública e gratuita, podendo servir de exemplo, motivação e até modelo para ações em outros municípios, estados ou até mesmo em âmbito federal ou internacional, que possam recriar essa ação, utilizar partes dela, se pautar ou se inspirar no próprio conceito da complementaridade entre as modalidades educativas.

É de se pensar que tal potencial esteja presente em incontáveis outras ações, atividades e projetos de ENF, existentes em nosso país, cabendo-nos refletir sobre caminhos para seu maior oferecimento, valorização e possibilidades de integração com a EF.

Entendemos que essa pesquisa oferece à área da educação a sua contribuição para abertura de um leque de reflexões acerca da relação de complementaridade entre ENF e $\mathrm{EF}$, no sentido de incentivar que novas propostas de criação e realização de ações visando uma educação integrada e mais ampla possam ser esboçadas.

Um caminho possível é exatamente o da Educação Integral, num sentido que ultrapasse a mera extensão do tempo de permanência dos alunos na escola, mas que entenda a educação como algo mais amplo, que vise à oportunização de vivências e experiências significativas e diversificadas durante o percurso de aprendizagem do ser humano.

Isso conduz a uma visão estendida e ampliada sobre a educação em nossa sociedade, que se nos afigura de que a ENF pode ocupar um espaço fixo e autônomo, e ao mesmo tempo complementar, na realização de uma aprendizagem mais efetiva, que não deixe de fora nenhum aspecto importante na formação do ser humano, em que se entenda a ENF, a EF e a informal, como um todo, de forma interligada, interdimensional, complexa e transdisciplinar, formando, ante as necessidades de nossa realidade atual, uma verdadeira Educação Humana, Humanizante e Humanizadora.

Muito há o que se intercambiar entre as modalidades educativas, e mais do que isso, entre as aprendizagens promovidas por elas. Nossa pesquisa e nossa reflexão nos revelaram isso. Esperamos que essa perspectiva aqui esboçada enseje que o cristal multifacetado, metáfora da educação, siga revelando mais cores e faça brilhar com mais intensidade aquelas já reveladas. 


\section{REFERÊNCIAS}

ÁGUAS DE SÃO PEDRO. Prefeitura Municipal. Lei municipal $\mathbf{n}^{\circ}$ 1640, de 08 de outubro de 2012. Cria na estrutura administrativa da Secretaria de Educação e Cultura o "Programa Educacional Girassol" e dá outras providências. Águas de São Pedro, 2012.

AQUINO-PEREIRA, M. J. Novas perspectivas da complementaridade entre educação não formal e formal. vislumbres do "Programa Educacional Girassol" em Águas de São Pedro. 2015. 228f. Dissertação (Mestrado em Educação) - Centro Universitário Salesiano (UNISAL), Americana, 2015.

BENNET, W. J. O livro das virtudes para crianças. Rio de Janeiro: Nova Fronteira, 1997.

BRANDÃO, C. R.. A canção das sete cores: educando para a paz. São Paulo: Contexto, 2005.

CHIZZOTTI, A. Pesquisa em ciências humanas e sociais. 3. ed. São Paulo: Cortez, 1998.

COOMBS, P. H. The world educational crisis. Nova York: Oxford University Press, 1968.

COOMBS, P. H.; AHMED, M. Attacking rural Poverty: How Non-formal Education Can Help. Baltimore: Johns Hopkins University Press, 1974.

FERNANDES, R. S.; GARCIA, V. A. Educação não formal campo de em formação. Revista Profissão Docente, Uberaba, v. 5, n. 13, p. 14-28, jan./set. 2006.

GADOTTI, M. La question de l'éducation formelle/non formelle. In:SÉMINAIRE DE INSTITUT INTERNATIONAL DES DROITS DE L'ENFAN, 11., 2005, Sion (Suiça). Actes... Sion (Suiça): IIDE, 2005.

GARCIA, V. A. Realismo da exclusão social. Revista de Ciências da Educação, v. 12, p. 113-131, 2005.

GOHN, M. G. Educação não-formal na pedagogia social.. In: CONGRESSO INTERNACIONAL DE PEDAGOGIA SOCIAL, 1., 2006. Anais... São Paulo: FE/USP, 2006.

GONÇALVES JUNIOR, L. Dialogando sobre a capoeira: possibilidades de intervenção a partir da motricidade humana. Motriz. Rio Claro, v. 15 n. 3 p. 700-707, 2009.

GONÇALVES JUNIOR, L.; RAMOS, G. N. S.; COUTO, Y. A. A motricidade humana na escola: da abordagem comportamental à fenomenológica. Revista Corpoconsciência, Santo André, v. 12, n. 2, p. 23-37, 2003.

IPEA. Atlas do IDHM revela evolução do Brasil em 20 anos, 2013. Disponível em <http://www.ipea.gov.br/portal/index.php?option=com_content\&id=19152>. Acesso em: 20 jan. 2016.

LOWENFELD, V. A criança e sua arte. 2. ed. São Paulo: Mestre Jou, 1977.

LUQUET, G. H. O desenho infantil. Porto: Civilização Editora, 1969.

MORIN, Edgar. Introdução ao pensamento complexo. 3. ed. Porto Alegre: Sulina, 2007.

PATTO, M. H. S. A produção do fracasso escolar: histórias de submissão e rebeldia. São Paulo: Casa do Psicólogo, 1999.

PILLAR, A.D. Desenho e escrita como sistemas de representação. Porto Alegre: Artes Médicas, 1996.

SÉRGIO, M. Alguns olhares sobre o corpo. Coleção: epistemologia e sociedade. Lisboa: Instituto Piaget, 2003.

SÉRGIO, M.; ROSÁRIO, A. T.; ALMADA, F.; VILELA, J.; TAVARES, M.V.; FEITOSA, A. M. O sentido e a acção. Lisboa: Instituto Piaget, 1999. 
SÉRGIO, M; TORO, S. La motricidad humana, un corte epistemológico de la educación física. En Acción Consentido, Universidad del Cauca, Popayán, v. 1, p. 101-109, 2005.

SIMSON, O. R. M.; PARK, M. B.; FERNANDES, R. S. Educação não-formal: um conceito em movimento. In: SIMSON, O. R. M. (Org.). Visões singulares, conversas plurais. São Paulo: Itaú Cultural, 2007. p. 13-42.

TRILLA, J. A educação não formal. In: GHANEM, E.; TRILLA, J. Educação formal e não-formal: pontos e contrapontos. Organizado por Valéria Amorim Arantes. São Paulo: Summus, 2008. p. 15-58.

Recebido em: 12 ago. 2019.

Aprovado em: 10 set. 2019. 